\title{
Validação de método para determinação das impurezas cascas e paus em café torrado e moído
}

\author{
Validation of a method to determine the impurities husks and straw \\ in roast ground coffee
}

\author{
Lumena Cunha Mendes ${ }^{1}$, Julio Cesar Freitas Santos ${ }^{2 *}$, Jessica Almeida Corrêa ${ }^{1}$, \\ Juarez Fabiano de Alkimim Filho', Danilo Vicente Reis da Silva ${ }^{3}$, Leonardo Nonato de Jesus ${ }^{1}$, \\ Wagner L. Souza Dibai ${ }^{3}$ \\ ${ }_{1}^{1}$ Ministério da Agricultura (MAPA), Laboratório Nacional Agropecuário (Lanagro), Pedro Leopoldo/MG - Brasil \\ 2 Embrapa Café, Brasilia/DF - Brasil \\ ${ }^{3}$ Instituto Mineiro de Agropecuária (IMA-MG), Pedro Leopoldo/MG - Brasil
}

\section{${ }^{*}$ Corresponding Author}

Julio Cesar Freitas Santos, Embrapa Café, Avenida W3 Norte, Parque Est. Biológica, CEP: 70770-901, Brasilia/DF - Brasil, e-mail: julio.cesar@embrapa.br

Cite as: Validation of a method to determine the impurities husks and straw in roast ground coffee. Braz. J. Food Technol., v. 18, e2015092, 2016.

Received: Nov. 19, 2015; Accepted: June 21, 2016

\section{Resumo}

A determinação de impurezas do café torrado e moído faz parte das análises que contribuem para assegurar o controle da qualidade do produto. O objetivo deste trabalho foi validar o procedimento metodológico de microscopia para detecção e quantificação das impurezas cascas e paus em café torrado e moído. O método baseou-se no princípio da extração de gordura do café com solvente orgânico, eliminação do pó fino por peneiração e determinação por catação pelo uso de microscópio estereoscópico. Setenta amostras de café torrado e moído coletadas em estabelecimentos comerciais de Belo Horizonte, MG, tiveram as análises duplicadas por três analistas, totalizando 420 determinações, com os resultados expressos em porcentagens das impurezas cascas e paus. Os coeficientes de variação em condições de repetibilidade variaram de $7,0 \%$ a $27,9 \%$, sendo considerados satisfatórios para microscopia. O fator analista tem forte influência nos parâmetros de precisão e exatidão do método. O método mostrou-se preciso a partir da concentração de 0,2\% de impurezas. A exatidão do método foi satisfatória com a recuperação estando numa faixa aceitável. As incertezas variaram com a faixa de concentração de impurezas e tenderam a ser inversamente proporcionais. O método foi considerado adequado para análise destas impurezas do café torrado e moído e tem potencial para ser indicado nos procedimentos de fiscalização.

Palavras-chave: Café torrado e moído; Análise do café; Microscopia do café; Impurezas do café.

\section{Summary}

The determination of impurities in roast ground coffee is part of the analyses that contribute to ensuring the control of product quality. The aim of this study was to validate the methodological procedure of microscopy to detect and quantify the impurities husks and straw in roast ground coffee. The method is based on the principle of organic solvent extraction of the coffee fat, elimination of the fine powder by screening and sorting of the impurities husks and straw by stereoscopic microscopy. Seventy samples of roast ground coffee were collected in commercial establishments in Belo Horizonte - MG Brazil and analysed in duplicate by three analysts, totalling 420 determinations, with the results expressed in percentages of the impurities husks and straw. The coefficients of variation under conditions of repeatability ranged from 7.0 to $27.9 \%$, being considered satisfactory for microscopy. The analyst factor had a strong influence on the precision and accuracy of the method. The method was shown to be accurate at concentrations above $0.2 \%$ impurities. The accuracy of the method was satisfactory and the recovery in an acceptable range. The uncertainties varied with the impurity concentration range and tended to be inversely proportional. The method was considered suitable for the analysis of these impurities in roast ground coffee, and has the potential to be indicated for use in inspection procedures.

Keywords: Roast ground coffee; Coffee analysis; Coffee microscopy; Coffee impurities. 


\section{Introdução}

Para incrementar a oferta de café com qualidade, promovendo o aumento do consumo interno e incentivo à exportação, devem ser monitoradas as propriedades físicas, químicas e sensoriais do produto (VEGRO et al., 2005) e realizadas iniciativas como a avaliação da qualidade de cafés regionais (TAVARES et al., 2012; SCHOLZ et al., 2011; LICCIARDI et al., 2005).

As ações para melhorar as características dos grãos verdes e do café torrado e moído possuem também o objetivo de monitorar e evitar a ocorrência de impurezas, decorrente da adição de cascas e paus e de sedimentos como terra, areia e torrões. As fraudes mais comuns são feitas com as matérias estranhas como milho, trigo e cevada (ASSAD et al., 2002; LOPEZ, 1983).

As impurezas surgem de forma proposital ou pela falta de boas práticas na produção, beneficiamento e industrialização, afetando a qualidade física, sensorial e sanitária do produto. Devido ao aspecto granuloso, escuro e oleoso do café, estas impurezas se tornam imperceptíveis, dificultando seu reconhecimento (INMETRO, 1998). Trabalhos de pesquisa usando diversas ferramentas objetivaram desenvolver novas metodologias para essas análises (TAVARES et al., 2012; OLIVEIRA et al., 2009; GODINHO et al., 2003; ASSAD et al., 2002; AMBONI et al., 1999).

O método comumente utilizado para detecção de impurezas e matérias estranhas no café torrado e moído consiste na preparação de amostras para análise visual em lâminas microscópicas com auxílio de um microscópio estereoscópico (LOPEZ, 1974; AOAC, 1995), sendo este indicado pela Associação Brasileira das Indústrias de Café (ABIC). Esse método de quantificação por microscopia apresenta algumas desvantagens por ser demorado e oneroso, além do fato de os reagentes químicos destruírem a amostra ou ser utilizado em menor volume, mascarando os resultados para o caso do café fraudado (ASSAD et al., 2002).

Para fiscalização da qualidade do café, exige-se a utilização de métodos validados que atendam a uma constante demanda analítica de avaliação de impurezas e fraudes. A validação do método analítico confere confiabilidade a uma metodologia, a um instrumento ou a um equipamento, e sua indicação garante confiabilidade e consistência dos resultados gerados, evidentemente se for operado e analisado de forma apropriada e tiver atendido às exigências dos procedimentos analíticos (MAGNUSSON; ÖRNEMARK, 2014; BRASIL, 2003; NATA, 1998; LEITE, 1996).

Registra-se em instituições oficiais fiscalizadoras a ausência de metodologias validadas, o que contribui para a não efetivação do monitoramento do café torrado e moído. Esse trabalho teve como objetivo validar o procedimento de microscopia em café torrado e moído, quanto à detecção e determinação das impurezas cascas, pertinentes ao fruto do café, e paus oriundos de fragmentos do caule do cafeeiro, visando viabilizar a efetivação de análises de rotina no controle de fraudes.

\section{Material e métodos}

As análises das impurezas cascas e paus do café torrado e moído foram realizadas na unidade de microscopia do Laboratório Nacional Agropecuário (LANAGRO) do Ministério da Agricultura, Pecuária e Abastecimento (MAPA), situado em Pedro Leopoldo, MG. Analisaram-se 70 amostras de café torrado e moído, duplicadas por três analistas, que totalizaram 420 determinações, expressas em porcentagens das impurezas cascas e paus. As amostras foram extraídas das embalagens de café torrado e moído, coletadas ao acaso no mercado de Belo Horizonte, MG, sem ter havido adição ou fortificação do seu conteúdo e sem haver conhecimento da presença e concentração de impurezas.

O método para detecção e determinação das impurezas foi desenvolvido por Lopez (1974), tendo este apresentado adaptação e detalhamento de procedimentos, conforme as seguintes etapas:

\subsection{Preparação e pesagem da amostra}

Depois da abertura da embalagem de $500 \mathrm{~g}$ de café torrado e moído, a massa do produto foi espalhada numa bandeja retangular de alumínio para a homogeneização, que foi movimentada com uma espátula no sentido das extremidades para o centro da bandeja. Posteriormente a massa foi dividida em quatro partes iguais por meio de dois cortes perpendiculares centrais, e misturados, dois a dois, os quadrantes diametralmente opostos. Em seguida, foi retirada da massa uma amostra de cerca de 2,0 g, que foi pesada em balança analítica de precisão e colocada numa placa de Petri, sendo a massa da pesagem da amostra anotada como massa total (mt).

\subsection{Extração de gordura do café}

Na capela de exaustão, foram colocados 60 a $80 \mathrm{~mL}$ de solvente clorofórmio p.a. num béquer de $250 \mathrm{~mL}$. Em seguida, com um bastão de vidro, transferiu-se a amostra de café da placa de Petri para o béquer com o solvente. O contato entre o café e o clorofórmio foi mantido por 20 minutos, sendo, a cada 5 minutos, agitado com o bastão de vidro. A seguir, foi realizada a filtração do clorofórmio por 10 minutos, vertendo a mistura de clorofórmio com café num papel de filtro etiquetado colocado sobre um funil de vidro de $75 \mathrm{~mm}$, para recolhimento do solvente em um erlemeyer de $250 \mathrm{~mL}$. Em seguida, o papel de filtro com a amostra desengordurada foi colocado numa placa 
de Petri e levado juntamente com o béquer e o bastão de vidro para secagem em estufa a $105^{\circ} \mathrm{C}$ por 30 minutos.

\subsection{Peneiração do pó fino da amostra}

Com um pincel de cerdas macias, foi realizada a transferência da amostra secada no papel de filtro para uma peneira de abertura de 80 mesh $(0,117 \mathrm{~mm})$, juntando-se os resíduos que estavam no bastão de vidro e no béquer. A peneira foi colocada sobre uma bandeja de alumínio para separação do pó fino, passando o pincel suavemente sobre o pó da amostra de café, para evitar a quebra das cascas presentes, dificultando assim sua identificação. Depois de todo o pó fino ter passado pela peneira, as partículas retidas foram transferidas para uma placa de Petri para pesagem da massa em gramas (mp) em balança analítica de precisão.

\subsection{Catação e cálculo das impurezas}

Uma alíquota de cerca de 0,1 g foi extraída da amostra retida na peneira e colocada na placa de Petri para ser pesada na balança analítica de precisão, e o peso da alíquota foi anotado como massa da catação (ma). Para identificação e catação das cascas e paus, foi utilizado um microscópio estereoscópico de aumento de 10 a 50x com luz refletida. A catação das impurezas na placa de Petri foi realizada com auxílio de estilete ou agulha com transferência destas para uma lâmina de vidro, contendo de duas a três gotas de água em sua superfície. Por diversas vezes, a massa da catação foi revolvida e molhada a ponta do estilete ou agulha para maior aderência das cascas e paus até que todas as impurezas fossem transferidas para a lâmina. Em seguida, foi feita a secagem da lâmina com as impurezas por 10 minutos na estufa para evaporação da água contida na lâmina. Depois da secagem da lâmina e sob o microscópio estereoscópico, foram retirados os grânulos de café que, por acaso, foram arrastados na catação. As cascas e os paus foram então transferidos para uma placa de Petri pequena tarada e mantida em estufa a $105^{\circ} \mathrm{C}$ por uma hora e, em seguida, no dessecador por 30 minutos para resfriamento. Depois da pesagem da placa de Petri mais as impurezas em balança analítica de precisão, foi calculada e anotada a massa das impurezas cascas e paus presente na alíquota catada (mi), após diminuição do peso da placa de Petri vazia. Para o cálculo da massa das impurezas cascas e paus na amostra peneirada (Miap), aplicou-se a fórmula: Miap $=\mathrm{mp} \times \mathrm{mi} / \mathrm{ma}$ com os valores de $\mathrm{mp}=$ massa da amostra peneirada total retida; ma = massa da alíquota da catação; $\mathrm{mi}=$ massa das impurezas na alíquota catada. A porcentagem de cascas e paus (\%CP) do café torrado e moído foi determinada pela fórmula: $(\% \mathrm{CP})=100 \times$ Miap $/ \mathrm{mt}$, sendo $\mathrm{mt}=$ massa total da amostra antes da extração da gordura do café.
Os parâmetros de avaliação da validação aplicados nas 420 determinações em porcentagens das impurezas cascas e paus do café torrado e moído envolveram a precisão de repetibilidade, precisão intermediária, exatidão e incerteza da medição. Os coeficientes de variação (CV) e desvios padrão dos resultados das análises foram calculados em seis faixas de concentração de impurezas cascas e paus, considerando o analista em cada uma das faixas de impurezas: menor que 0,20\%; de 0,20\% a 0,50\%; de $0,50 \%$ a $1,50 \%$ : de $1,50 \%$ a $3,0 \%$; de $3 \%$ a $5 \%$; maior que $5,0 \%$

\subsection{Determinação da precisão sob condições de repetibilidade}

A precisão dentre os parâmetros de validação corresponde ao grau de concordância entre indicações ou valores medidos, obtidos por medições repetidas, no mesmo objeto ou em objetos similares, sob condições específicas (INMETRO, 2009). Para determinação da precisão do método sob condições de repetibilidade, os três analistas envolvidos duplicaram as análises de cada amostra, submetendo-as a seis análises sucessivas. $\mathrm{O}$ índice de precisão foi numericamente expresso em desvio padrão relativo (RSD\%) e coeficiente de variação (CV\%), conforme a consolidação da avaliação dos resultados das análises das amostras estratificadas nas seis faixas de concentração de impurezas.

\subsection{Determinação da precisão sob condições intermediárias}

As amostras analisadas tiveram seus resultados agrupados nas seis faixas de concentração de impurezas. Como o método microscópico depende muito da experiência e habilidade dos analistas, tornou-se importante avaliar a precisão do método nas diferentes faixas e com diferentes analistas, para verificar se os desvios obtidos estavam dentro de uma faixa aceitável.

\subsection{Avaliação comparativa dos três analistas}

Para esta validação, foram selecionados três analistas com capacidade para executar todas as etapas do processo metodológico, possibilitando ainda a obtenção de uma razoável variabilidade e boa estimativa da reprodutibilidade do método. Na comparação dos três analistas, foram utilizados testes não paramétricos, uma vez que os pressupostos básicos da análise de variância e teste t-Student não foram verificados. Na estatística não paramétrica, foi utilizado o teste de Kruskal-Wallis, empregado para comparar três ou mais amostras independentes em relação a uma medida de interesse. Este teste baseia-se nos postos ou posições das medidas, ou seja, na posição do indivíduo na amostra (SIEGEL; CASTELLAN JUNIOR, 2006). 


\subsection{Avaliação da exatidão das análises}

Na avaliação da exatidão das análises, foram descritas a recuperação geral e o desvio padrão e a recuperação obtida pelos analistas com o respectivo desvio padrão, em duas faixas de concentração de resultados: menor que $1,0 \%$ e maior que $1,0 \%$ de impurezas.

\subsection{Estimativa da incerteza da medição}

A incerteza de medição foi determinada a partir de metodologia simplificada por composição da estratégia de Botton-Up e Top-Down (EURACHEM, 2002). A incerteza expandida foi obtida a partir da incerteza combinada multiplicada pelo fator de abrangência k. A incerteza combinada foi calculada levando-se em conta a equação do mensurando e as principais fontes de incerteza encontradas, como a incerteza da balança e a incerteza associada à precisão do método de ensaio.

As seguintes fórmulas foram utilizadas no cálculo da incerteza relacionada à balança e à precisão do método, com inclusão dos cálculos das incertezas combinada e expandida, calculadas por faixas de concentração de impurezas das amostras.

Incerteza da balança: $u_{m}=\sqrt{2\left(u_{\text {Bal }}^{\text {Calib }}\right)^{2}+2\left(u_{\text {Bal }}^{\text {Rep }}\right)^{2}}$

Incerteza associada à precisão do método: $\mathrm{u}_{\text {(precisão) }}=\frac{\mathrm{S}}{\sqrt{\mathrm{n}}}$

Incerteza combinada: $u_{c}=\sqrt{ }\left(u_{m}^{2}+u_{\text {precisão }}^{2}\right)$

Incerteza expandida: $\mathrm{u}_{\mathrm{e}}=\mathrm{k} \times \mathrm{u}_{\mathrm{c}}$

Onde: $u_{m}$ é a incerteza ligada à balança;

$u_{\text {(precisão) }}$ é a incerteza associada à precisão do método;

$u_{c}$ é a incerteza combinada;

$u_{e}$ é a incerteza expandida;

k é o fator de abrangência.

Para obtenção da estimativa da incerteza nos diferentes níveis de concentração das impurezas, optou-se por dividir os resultados das análises das amostras em faixas de concentração de impurezas, estimando-se uma incerteza para cada faixa.

\section{Resultados e discussão}

$\mathrm{Na}$ determinação da precisão sob condições de repetibilidade, considerando a estratificação dos resultados das análises nas seis faixas de concentração das impurezas, verificou-se que os coeficientes de variação apresentaram valores no intervalo de $7,0 \%$ a $27,9 \%$, em que, respectivamente, o menor valor de $7,0 \%$ equivaleu à faixa de concentração de 1,5\% a 3,0\% e o maior valor de $27,9 \%$ correspondeu à faixa de concentração de 0,20\% a 0,50\% (Tabela 1).
Os coeficientes de variação foram considerados satisfatórios principalmente por se tratar de um método microscópico inerente à catação de impurezas, realizada manualmente e sujeita a variações na homogeneidade das determinações. A precisão deste tipo de método neste ensaio não pode ser comparada com aquela obtida por métodos automatizados, entretanto, como os coeficientes de variação permaneceram abaixo de 30\%, consideraram-se esses resultados compatíveis com o objetivo pretendido nas análises de impurezas do café torrado e moído. Para métodos microscópicos, a referência nos embasa para um desvio padrão maior que este, embora se considere ideal uma variabilidade em torno de $20 \%$ a $25 \%$ (CODEX ALIMENTARIUS, 2005; INMETRO, 2010).

Esses resultados combinam com o trabalho de Santos et al. (2013) sobre as avaliações iniciais da precisão e aplicação do método de microscopia na determinação de impurezas do café torrado e moído, cujo coeficiente de variação de 22,5\% foi plenamente aceitável.

$\mathrm{Na}$ determinação da precisão sob condições de precisão intermediária, a variabilidade dos resultados diminui significativamente à medida que se aumenta a concentração média das impurezas de cascas e paus, implicando que a precisão aumenta consideravelmente nas faixas de resultados de maior concentração de impurezas (Tabela 2).

Tabela 1. Média, desvio padrão e coeficiente de variação (CV) na análise da precisão sob condições de repetibilidade, considerando a faixa de concentração de impurezas.

\begin{tabular}{|c|c|c|c|}
\hline $\begin{array}{c}\text { Faixa de } \\
\text { concentração } \\
(\%)\end{array}$ & $\begin{array}{c}\text { Média } \\
(\%)\end{array}$ & $\begin{array}{c}\text { Desvio } \\
\text { Padrão } \\
(\%)\end{array}$ & $\begin{array}{l}\text { CV } \\
(\%)\end{array}$ \\
\hline$<0,20$ & 0,20 & 0,03 & 16,7 \\
\hline $0,20-0,50$ & 0,36 & 0,10 & 27,9 \\
\hline $0,50-1,50$ & 1,38 & 0,26 & 19,0 \\
\hline $1,50-3,00$ & 2,16 & 0,15 & 7,0 \\
\hline $3,00-5,00$ & 3,61 & 0,43 & 11,8 \\
\hline$>5,00$ & 6,31 & 0,49 & 7,7 \\
\hline
\end{tabular}

Tabela 2. Média, desvio padrão, coeficiente de variação (CV) e número de amostra (n) na análise da precisão sob condições intermediárias conforme concentração de impurezas.

\begin{tabular}{ccccc}
$\begin{array}{c}\text { Faixa de } \\
\text { Concentração } \\
(\%)\end{array}$ & $\begin{array}{c}\text { Média } \\
\mathbf{( \% )}\end{array}$ & $\begin{array}{c}\text { Desvio } \\
\text { Padrão } \\
\mathbf{( \% )}\end{array}$ & $\begin{array}{c}\mathbf{C V} \\
\mathbf{( \% )}\end{array}$ & $\mathbf{n}$ \\
\hline 0,20 & 0,12 & 0,08 & 66,0 & 108 \\
$0,20-0,50$ & 0,37 & 0,16 & 44,3 & 46 \\
$0,50-1,50$ & 0,89 & 0,32 & 35,6 & 80 \\
$1,50-3,00$ & 2,12 & 0,62 & 29,0 & 66 \\
$3,00-5,00$ & 3,98 & 0,76 & 19,0 & 34 \\
$>5,00$ & 7,18 & 1,11 & 15,4 & 24 \\
\hline
\end{tabular}


Entretanto, esse resultado divergiu daquele obtido por Gonçalves et al. (2007), que verificaram perda acentuada da precisão na validação intralaboratorial de um método por imagem, na detecção e quantificação dessas impurezas em concentrações maiores.

Verificou-se que o coeficiente de variação mais alto $(66,0 \%)$ foi obtido na faixa de amostras com concentração de até $0,20 \%$ de impurezas, o que foi indicativo de que a variabilidade de medição nesta faixa é alta e que a confiabilidade da quantificação de impurezas é questionável. Entretanto, nas faixas acima de $0,20 \%$ de impurezas, os coeficientes de variação de precisão intermediária obtidos são aceitáveis, mostrando a adequação do método. Nas condições de precisão intermediária, houve efeito da variação do número de analistas, período de tempo e concentração de impurezas das amostras, cujos resultados apresentaram variabilidade significativamente maior. A quantificação de amostras de café torrado e moído acima de $0,20 \%$ atende ao uso pretendido para o método, pois, apesar da inexistência de referências para o café que estabeleçam limites para precisão intermediária, são aceitáveis desvios de reprodutibilidade abaixo de $40 \%$, inclusive para métodos mais acurados como a cromatografia (BRASIL, 2011).

Na comparação do desempenho dos três analistas, verificou-se que não houve diferença significativa entre os analistas 2 e 3 e entre os analistas 2 e 1 , mas observou-se diferença entre os analistas 1 e 3 , implicando a comprovação da importância do fator analista na determinação dos parâmetros de precisão e exatidão do método (Tabela 3).

Com base na precisão intermediária, os resultados dos analistas foram levados em conta de forma que toda a variação estivesse contida nos resultados da precisão do método. Caso apenas um analista fosse utilizado, não seria possível estabelecer uma precisão que representasse a variação do método. Quanto ao desempenho comparativo dos três analistas, verificou-se que o analista 2 foi quem apresentou os resultados mais confiáveis, mesmo não diferindo estatisticamente de nenhum dos outros.

$\mathrm{Na}$ exatidão das análises, a recuperação geral ficou dentro da expectativa, principalmente na faixa de resultados acima de $1,0 \%$ de impurezas. Como a quantificação é mais difícil na faixa abaixo de 1,0\%, existiu um reflexo significativo na exatidão dos resultados (Tabela 4). Mesmo assim, a recuperação média de $121 \%$, obtida nestas condições, pode ser considerada adequada, principalmente se levarmos em conta que não existe disponibilidade de material de referência certificado para essas análises de café torrado e moído, que pudesse ser utilizado no cálculo da veracidade da exatidão. A recuperação na faixa acima de 1,0\% foi considerada satisfatória estando dentro do limite de $120 \%$.

Por se tratar de um método microscópico de análise de impurezas, é considerado um método subjetivo, que está susceptível a erros humanos e, portanto, dependente inteiramente da experiência do analista (ASSAD et al., 2002; AMBONI et al., 1999).

$\mathrm{Na}$ avaliação de recuperação de forma individual, todos os analistas obtiveram médias satisfatórias com exceção do analista 2 na faixa de concentração de impurezas abaixo de 1,0\% (Tabelas 5-7). Nesta faixa, devido à maior variabilidade dos resultados, existiu realmente maior dificuldade em se obter resultados repetitivos e, consequentemente, uma clara tendência a problemas de recuperação. Como o método é baseado em catação de cascas e paus, nas faixas de baixa concentração dessas impurezas, a diferença de um fragmento catado a mais ou a menos tem forte influência sobre o resultado (SANTOS et al., 2013). A faixa ótima de recuperação situa-se acima de 1,0\%.

$\mathrm{Na}$ verificação da estimativa da incerteza da medição, observou-se que a incerteza variou conforme a faixa de concentração de impurezas (Tabela 8). Este fato era esperado, pois a dispersão dos resultados em termos percentuais tende a ser maior nas amostras com baixa concentração de impurezas cascas e paus. Equações de função quadrática e exponencial, para a predição

Tabela 3. Comparação de desempenho entre os três analistas das avaliações de validação de metodologia para determinação de impurezas em café torrado e moído.

\begin{tabular}{lccc} 
Fator Comparativo & $\begin{array}{c}\text { Diferença } \\
\text { Observada }\end{array}$ & $\begin{array}{c}\text { Diferença } \\
\text { Crítica }\end{array}$ & $\begin{array}{c}\text { Diferença } \\
\text { Significativa }\end{array}$ \\
\hline Analista 2 - Analista 3 & 6,50 & 13,86 & Não \\
Analista 2 - Analista 1 & 10,59 & 13,86 & Não \\
Analista 1 - Analista 3 & 17,09 & 13,86 & Sim \\
\hline
\end{tabular}

Teste de Kruskal-Wallis: valores de quiquadrado 8,887014153; grau de liberdade 2 e P 0,011754642.

Tabela 4. Recuperação geral e desvio padrão da recuperação geral na avaliação da exatidão das análises de microscopia do café torrado e moído por faixa de concentração.

\begin{tabular}{ccc}
$\begin{array}{c}\text { Faixa de } \\
\text { Concentração }\end{array}$ & $\begin{array}{c}\text { Recuperação } \\
\text { Média }\end{array}$ & $\mathbf{S}_{\text {(RECUPERAÇÃo) }}$ \\
$\mathbf{( \% )}$ & $\mathbf{( \% )}$ & $\mathbf{( \% )}$ \\
$<1,0$ & 121,47 & 70,68 \\
$>1,0$ & 114,07 & 29,04 \\
\hline
\end{tabular}

Tabela 5. Recuperação média e desvio padrão da recuperação do analista 1 por faixa de concentração.

\begin{tabular}{ccc}
$\begin{array}{c}\text { Faixa de } \\
\text { Concentração }\end{array}$ & $\begin{array}{c}\text { Recuperação } \\
\text { Média }\end{array}$ & $\mathbf{S}_{\text {(RECUPERAÇÃo) }}$ \\
$\mathbf{( \% )}$ & $\mathbf{( \% )}$ & $\mathbf{( \% )}$ \\
$<1,0$ & 106,30 & 52,68 \\
$>1,0$ & 104,18 & 32,88 \\
\hline
\end{tabular}


Validação de método para determinação das impurezas cascas e paus em café torrado e moído Mendes, L. C. et al.

Tabela 6. Recuperação média e desvio padrão da recuperação do analista 2 por faixa de concentração.

\begin{tabular}{ccc}
$\begin{array}{c}\text { Faixa de } \\
\text { Concentração }\end{array}$ & $\begin{array}{c}\text { Recuperação } \\
\text { Média }\end{array}$ & $\begin{array}{c}\mathbf{S}_{\text {(RECUPERAÇÃo) }} \\
\text { (\%) }\end{array}$ \\
$\mathbf{( \% )}$ & $\mathbf{( \% )}$ & 84,51 \\
$<1,0$ & 166,02 & 33,33 \\
\hline 1,0 & 111,25 & \\
\hline
\end{tabular}

Tabela 7. Recuperação média e desvio padrão da recuperação do analista 3 por faixa de concentração.

\begin{tabular}{ccc}
$\begin{array}{c}\text { Faixa de } \\
\text { Concentração }\end{array}$ & $\begin{array}{c}\text { Recuperação } \\
\text { Média }\end{array}$ & $\begin{array}{c}\mathbf{S}_{\text {(RECUPERAÇÃo) }} \\
\text { (\%) }\end{array}$ \\
$\mathbf{( \% )}$ & $\mathbf{( \% )}$ & 83,70 \\
$<1,0$ & 119,41 & 42,48 \\
\hline
\end{tabular}

Tabela 8. Incerteza combinada $\left(u_{c}\right)$, fator de abrangência $(k)$ e incerteza expandida $\left(u_{e}\right)$ por faixa de concentração de impurezas cascas e paus em café torrado e moído.

\begin{tabular}{cccc}
$\begin{array}{c}\text { Faixa de } \\
\text { Impurezas }\end{array}$ & $\begin{array}{c}\text { Incerteza } \\
\text { Combinada }\end{array}$ & $\begin{array}{c}\text { Fator de } \\
\text { Abrangência }\end{array}$ & $\begin{array}{c}\text { Incerteza } \\
\text { Expandida }\end{array}$ \\
$\begin{array}{c}\text { (\%) } \\
x \leq 0,20\end{array}$ & $\mathbf{( \% )}$ & $\mathbf{( k )}$ & $\mathbf{( \% )}$ \\
$0,20<x \leq 0,50$ & 0,08 & 1,98 & 0,05 \\
$0,50<x \leq 1,50$ & 0,09 & 2,01 & 0,16 \\
$1,50<x \leq 3,00$ & 0,28 & 2,99 & 0,18 \\
$3,00<x \leq 5,00$ & 0,28 & 2,57 & 0,73 \\
$x>5,00$ & 0,49 & 2,57 & 0,71 \\
\hline
\end{tabular}

da incerteza em função do nível de concentração foram inicialmente calculadas, mas os resultados não indicaram um ajuste aceitável dos modelos, sendo recomendada a utilização na rotina analítica da incerteza por faixas.

\section{Conclusão}

As incertezas variam com a faixa de concentração de impurezas e tendem a ser inversamente proporcionais à sua concentração. A exatidão e a precisão do método de microscopia do café torrado e moído foram satisfatórias a partir da concentração de $0,2 \%$ das impurezas cascas e paus. O método foi considerado adequado para análise destas impurezas do café torrado e moído e tem potencial para ser indicado nos procedimentos de fiscalização.

\section{Referências}

AMBONI, R. D. M. C.; FRANCISCO, A.; TEIXEIRA, E. Utilização de microscopia eletrônica de varredura para detecção de fraudes em café torrado e moído. Ciência e Tecnologia de Alimentos, Campinas, v. 19, n. 3, p. 311-313, 1999.

ASSAD, E. D.; SANO, E. E.; CUNHA, S. A. R.; CORREA, T. B. S.; RODRIGUES, H. R. Identificação de impurezas e misturas em pó de café por meio de comportamento espectral e análise de imagens digitais. Pesquisa Agropecuaria Brasileira, Brasília, v. 37, n. 2, p. 211-216, 2002. http://dx.doi.org/10.1590/S0100204X2002000200013.

ASSOCIATION OF OFFICIAL ANALYTICAL CHEMISTS - AOAC. Official methods filth in ground coffees and coffee substitutes sub chapter 2. In: AOAC. Beverages and beverage materials 16th. ed. Gaithersburg: AOAC, 1995. v. 2, 98 p.

BRASIL. Ministério da Agricultura, Pecuária e Abastecimento. Instrução normativa $n^{\circ}$ 9, de 27 de junho de 2003. Diário Oficial [da] República Federativa do Brasil, Brasília, DF, 30 jun. 2003. Seção 1, p. 4. Disponível em: <http://extranet.agricultura.gov. $\mathrm{br} /$ sislegis-consulta/consultarLegislacao. do?operacao=visuali zar\&id=1398 $>$. Acesso em: 06 maio 2013.

BRASIL. Ministério da Agricultura, Pecuária e Abastecimento. Manual de garantia da qualidade analítica. Brasília: MAPA/ ACS, 2011. 227 p.

CODEX ALIMENTARIUS. Guidelines on good laboratory practice in residue analysis: CAC/GL 40-1993. Roma, 2005, v. 1, 36 p.

EURACHEM. Primeira edição do guia EURACHEM / CITAC: determinando a incerteza nas medições analíticas. 2. ed. Leoben: EURACHEM, 2002.

GODINHO, A.; OLIVEIRA, L. S.; FERRAZ, V. P.; FRANÇA, A. $S$. Detecção e quantificação de impurezas em café torrado e moído. Revista Brasileira de Armazenamento, Viçosa, n. 7 , p. 50-55, 2003. Especial Café

GONÇALVES, E. B.; CORRÊA, T. B. S.; ASSAD, E. D.; RODRIGUES, H. R.; SANO, E. E.; CUNHA, S. A. R.; SOUZA, M. L. M.; LOPES, J. R. H. Validação intralaboratorial de método por imagem para detecção e quantificação de impurezas em café torrado e moído: cascas e paus como exemplo. Brazilian Journal Food Technology, Campinas, v. 10, n. 2, p. 144-150, 2007.

INSTITUTO NACIONAL DE METROLOGIA, QUALIDADE E TECNOLOGIA - INMETRO. DOQ-CGCRE-008: orientação sobre validação de métodos analíticos. Rio de Janeiro, 2010. 20 p.

INSTITUTO NACIONAL DE METROLOGIA, QUALIDADE E TECNOLOGIA - INMETRO. Café torrado e moído. Rio de Janeiro, 1998. Relatório. Disponível em: <http://www.inmetro.gov.br/ consumidor/produtos/cafe.asp>. 1998. Acesso em: 10 jan. 2012.

INSTITUTO NACIONAL DE METROLOGIA, QUALIDADE E TECNOLOGIA - INMETRO. VIM - Vocabulário Internacional de Metrologia: conceitos fundamentais e gerais e termos associados. Rio de Janeiro, 2009. 78 p.

LEITE, F. Validação em análise química. Campinas: Átomo, 1996. $124 \mathrm{p}$.

LICCIARDI, R.; PEREIRA, R. G. F. A.; MENDONÇA, L. M. V. L.; FURTADO, E. F. Avaliação físico-química de cafés torrados e moídos, de diferentes marcas comerciais, da região sul de Minas 
Validação de método para determinação das impurezas cascas e paus em café torrado e moído

Mendes, L. C. et al.

Gerais. Ciência Tecnologia de Alimentos, Campinas, v. 25, n. 3, p. 425-429, 2005.

LOPEZ, F. C. Determinação do sedimento, cascas e paus no café torrado e moído. Revista do Instituto Adolfo Lutz, São Paulo, v. 34, p. 29-34, 1974.

LOPEZ, F. C. Determinação quantitativa das principais substâncias utilizadas para fraudar o café torrado e moído. Revista do Instituto Adolfo Lutz, São Paulo, v. 43, n. 1/2, p. 3-8, 1983.

MAGNUSSON, B.; ÖRNEMARK, U. (Ed.). EURACHEM guide: the fitness for purpose of analytical methods: a laboratory guide to method validation and related topics. 2nd ed. Leoben: EURACHEM, 2014. Disponível em: <http://www.eurachem.org>. Acesso em: 06 maio 2013.

NATIONAL ASSOCIATION OF TESTING AUTHORITIES - NATA. NATA technical note 17 - 1998: format and contents of test methods and procedures for validation and verification of chemical tests methods. Sidney, 1998. 8 p.

OLIVEIRA, R. C. S.; OLIVEIRA, L. S.; FRANCA, A. S.; AUGUSTI, R. A. A preliminary evaluation of the potential of SPME-GC-MS and chemo metrics to detect adulteration of ground roasted coffee with roasted barley. Journal of Food Composition and Analysis, San Diego, v. 22, n. 3, p. 257-261, 2009. http://dx.doi. org/10.1016/j.jfca.2008.10.015.
SANTOS, J. C. F.; ALKMIM FILHO, J. F.; SILVA, D. V. R.; MENDES, L. C.; CORREA, J. A.; DIBAI, W. L. S. Avaliação da precisão e aplicação de método para determinação de impurezas do café torrado e moído. In: SIMPÓSIO DE PESQUISA DOS CAFÉS DO BRASIL, 8., 2013, Salvador. Anais... Brasília, DF: Embrapa Café, 2013. 5 p.

SCHOLZ, M. B. S.; FIGUEIREDO, V. R. G.; SILVA, J. V. N.; KITZBERGER, C. S. G. Características físico-químicas de grãos verdes e torrados de cultivares de café (Coffea arabica L.) do IAPAR. Coffee Science, Lavras, v. 6, n. 3, p. 245-255, 2011.

SIEGEL, S.; CASTELLAN JUNIOR, N. J. Estatística não paramétrica para as ciências do comportamento. São Paulo: Artmed-Bookman, 2006.

TAVARES, K. M.; PEREIRA, R. G. F. A.; NUNES, C. A.; PINHEIRO, A. C. M. Espectroscopia no infravermelho médio e análise sensorial aplicada à detecção de adulteração de café torrado por adição de cascas de café. Química Nova, São Paulo, v. 35, n. 6, p. 1164-1168, 2012.

VEGRO, C. L. R.; PINO, F. A.; MORICOCHI, L.; NOGUEIRA JUNIOR, S. Restrições à exportação de café torrado e moído. Organizações Rurais \& Agroindustriais, Lavras, v. 7, n. 2, p. 214-226, 2005. 